\title{
La persistencia de los
}

hacendados azucareros del

estado de Morelos frente al

reparto agrario, 1920-1930.

Un estudio de caso

Carlos Barreto Zamudio ${ }^{1}$

carlos.barreto@uaem.mx

DOI: https://dx.doi.org/10.31836/lh.20.7148
The persistence of the sugar hacendados of Morelos state in front of the agrarian distribution, 1920-1930. A case study

\section{Resumen}

Al finalizar la Revolución, en el estado de y solicitudes de indemnización. También Morelos se dieron una serie de acontecimientos que desmantelaron el poderoso sistema de haciendas azucareras. Los hacendados buscaron mecanismos para frenar los efectos del reparto agrario sobre sus fincas y reconstruir la industria azucarera. Recurrieron a la vía legal implementando amparos, juicios civiles emplearon contratos de arrendamiento que garantizaran el reconocimiento de su propiedad sobre las tierras y que éstas no fueran declaradas como ociosas. El artículo muestran ejemplos de una etapa temprana del reparto agrario en el oriente de Morelos: las haciendas de Santa Ana Tenango y Santa Clara Montefalco.

Palabras clave: Haciendas, reparto agrario, amparo, arrendamiento, zapatismo.

\section{Abstract}

At the end of the Revolution, a series of events took place in the state of Morelos that dismantled the powerful system of sugar haciendas. The hacienda owners sought mechanisms to curb the effects of agrarian distribution on their farms and rebuild the sugar industry. They appealed to the legal route, implementing legal protections, civil lawsuits and requests for compensation. They also used leasing contracts that guaranteed recognition of their ownership of the land and that the land was not declared idle. The article shows examples of this activity at an early stage of agrarian distribution in the east of Morelos: the haciendas of Santa Ana Tenango and Santa Clara Montefalco.

Keywords: Haciendas, agrarian distribution, judicial protection, lease, zapatismo.

1 Universidad Autónoma del Estado de Morelos, México.

Av. Universidad 1001, Col. Chamilpa, C.P. 62209, Edificio 19, Cuernavaca, Morelos, México. 


\section{Introducción}

El final de la etapa armada de la Revolución Mexicana en el estado de Morelos trajo consigo la extinción de las haciendas azucareras, cuyos orígenes se remontaban al distante periodo cortesiano. La Constitución de 1917 y la derrota militar del zapatismo acompañaron el final de una forma de vida mediada por el trabajo en las haciendas, que por siglos caracterizó la vocación productiva de la región a pesar del conflicto social que generaba. Antes del estallido revolucionario, como señala Horacio Crespo en su estudio acerca de la etapa de modernización acelerada de la hacienda azucarera en el estado de Morelos entre 1880 y 1910, la entidad era reconocida por su producción azucarera dotada de avances tecnológicos, poderío financiero y ventajas competitivas en los ámbitos nacional e internacional (Crespo, 2009). La lucha armada, sin embargo, devastó la planta productiva, la obra hidráulica y los campos, lo que en el corto y mediano plazo resultó en la imposibilidad para restablecer el cultivo cañero y la explotación azucarera a gran escala.

En Morelos, la atención a las demandas revolucionarias arrojó nuevas y, muchas veces, contradictorias medidas sobre el problema de la tierra. Pero cuando los hacendados de Morelos percibieron que sus empresas, de por si dañadas por la guerra, podían ser severamente afectadas por las disposiciones agrarias revolucionarias, buscaron los mecanismos para rehacerse pensando en la reconstrucción del escenario azucarero. Al inicio de los años 20 aún había esperanza, pues además de la vehemencia de los propietarios, las disposiciones legales generadas por grupos revolucionarios opositores al zapatismo colocados en el poder nacional, no se orientaron a resolver el problema agrario morelense desde la óptica del Plan de Ayala. En una etapa temprana, el reparto agrario fue lento, desorganizado, más bien conservador y acompañado de una intrincada jurisprudencia (James, 1910). Hasta antes de la unificación revolucionaria, planes, leyes y decretos, así como la propia Constitución de 1917, reflejaron tensiones entre posturas políticas provenientes de corrientes revolucionarias confrontadas que, en materia agraria, muchas veces tendieron a retomar el estado de cosas anterior al estallido armado.

El objetivo del presente artículo es ejemplificar la forma en que actuaron los hacendados del estado de Morelos para protegerse por la vía legal de las medidas agrarias resultantes del proceso revolucionario durante los primeros años de la década de 1920 y del marcado declive en el sistema de haciendas hacia el inicio de la década de los 30. Para ello mostramos elementos del recurso de amparo promovido por los propietarios de las haciendas de Santa Ana Tenango y Santa Clara Montefalco contra las 
afectaciones que sobre sus propiedades generó la Ley de Tierras Ociosas del 23 de junio de 1920 promulgada durante la presidencia de Adolfo de la Huerta, así como datos provenientes de juicio civil

En términos generales, los propietarios optaron por la vía legal para salvaguardar sus haciendas. Fue notable la cantidad de amparos y juicios civiles interpuestos por los hacendados del país -y específicamente de Morelos- contra el reparto agrario. Además de ello, en el terreno del usufructo de la tierra, los empresarios del azúcar se mantuvieron activos para demostrar su propiedad y capacidad de trabajo sobre los terrenos de cultivo. Echaron mano de contratos de arrendamiento para garantizar que se les reconociera dicha propiedad sobre las tierras y evitar que fueran declaradas como ociosas, es decir, puestas a disposición del interés nacional.

Para este trabajo utilizamos, como fuentes primarias, expedientes históricos resguardados en la Casa de Cultura Jurídica de Cuernavaca, dependiente de la Suprema Corte de Justicia de la Nación. La perspectiva que ofrecen estos expedientes es inestimable como fuente historiográfica especialmente para el análisis de un periodo nebuloso, como el que representan los años 20 en el estado de Morelos. Aunque aún puede considerarse que los archivos judiciales son escasamente utilizados como fuente primaria, éstos proveen información relevante para el estudio histórico del conflicto social desde el punto de vista de la justicia.Los archivos judiciales registran conflictos entre intereses y posturas que se desahogan en el ámbito institucional de la justicia (Durán, 1999: s/p). En específico el amparo, caso de uno de los expedientes clave de este trabajo, involucra a alguna autoridad que funge como responsable, por algún abuso o mala interpretación de "los derechos y reivindicaciones de distinto tipo en un ámbito del propio Estado" (Durán, 1999: s/p).

Por otra parte, el artículo pretende aportar a la historia rural del Morelos postzapatista y de la etapa temprana de la reforma agraria del siglo XX mexicano. Como ha señalado recientemente Emilio Kourí, el tema agrario mexicano pasó de ser uno de los pilares de la historiografía mexicana a mostrar un evidente declive, proceso que durante las dos últimas décadas se ha ido revirtiendo de manera lenta, incipiente y fragmentaria, pero que permite revisar de manera crítica la "narrativa hegemónica" de la historia agraria mexicana (Kourí, 2017). Es por ello necesario insistir en estudios locales, regionales y fuentes renovadas que aporten a la revisión de las tradiciones historiográficas agrarias, como queda esbozado con la obra coordinada por Antonio Escobar Ohmstede y Mathew Butler Mexico in transition (2013). El ordenamiento y puesta en servicio de fondos documentales de archivos locales e instituciones como la Suprema Corte de 
Justicia de la Nación, el Archivo General Agrario o el Archivo Histórico del Agua continúa abriendo rutas para su estudio, replanteando la importancia del campo mexicano, así como la abundancia y la diversidad de los actores sociales implicados.

Sin duda, el estado de Morelos es uno de los espacios geográficos privilegiados para el estudio del mundo rural mexicano, y donde más ha perdurado la dicotomía pueblos-haciendas, sobre todo para explicar el estallido revolucionario, aunque la diversidad de trabajos es amplia. Sin pretender una relación exhaustiva, encontramos obras seminales y textos clave como los de Felipe Ruiz de Velasco (1937); Jesús Sotelo Inclán (1943); John Womack (1969); Arturo Warman (1976); Horacio Crespo (2000) y (2009); Salvador Rueda Smithers (1999); Francisco Pineda (1997); y Felipe Ávila (2001). A nivel local también tenemos los textos de Valentín López González (2001); Laura Valladares en (2003) y Alejandro Tortolero (2008), quienes han insistido en abordar la dimensión hidráulica del entorno rural morelense. El presente artículo de alguna forma es deudor de esta tradición historiográfica.

El trabajo se divide en dos partes. En el primer apartado, a modo de contexto, se definen las etapas de la lucha zapatista relacionadas con la desarticulación del latifundio en Morelos. Estas podrían sintetizarse en: los tiempos del reparto zapatista, la promulgación de la Constitución de 1917, la derrota militar del zapatismo, el asesinato de Zapata, la disolución del Ejército Libertador del Sur, la alianza de los remanentes zapatistas con los sonorenses y la vuelta al orden constitucional en el año 1930. Ese periodo se caracterizó por la pugna entre la propuesta zapatista y la permanencia del viejo régimen de propiedad basado en las haciendas que encontraría su fin en este periodo.

El segundo apartado denominado Amparo y arrendamiento corresponde a la argumentación central: la defensa jurídica que emprendieron los hacendados ante lo que consideraban abusos de las autoridades y el uso del arrendamiento como estrategia para comenzar la reorganización de la hacienda azucarera en Morelos en una etapa temprana de la reforma agraria. Para ello, hacemos el estudio contextualizado de un amparo que Luis García Pimentel Elguero promovió en el año de 1921 contra actos del presidente municipal de Tepalcingo, por la aplicación de la Ley de Tierras Ociosas de 1920 promulgada durante el periodo presidencial de Adolfo de la Huerta. ${ }^{2}$ A partir de los años 20, Luis García Pimentel Elguero, a nombre de su padre, Luis García Pimentel Sr., propietario de las AHCCJ-Mor.) Amparos, Exp. 34, No. 1353, 1921. 
haciendas de Santa Ana Tenango y Santa Clara Montefalco, actuó por la vía legal para frenar los efectos del reparto agrario en sus propiedades. Fue un contexto caracterizado por contradicciones e interpretaciones legales el que acompañó el final de las haciendas y el final del sistema de haciendas en el estado de Morelos.

\section{El reparto agrario sin Zapata}

Al inicio de la década de 1920, aún fresco el asesinato de Emiliano Zapata, en Morelos comenzaron a verse los efectos del final de la etapa armada de la lucha zapatista, marcada por la devastadora persecución militar emprendida por la obra de pacificación del carrancismo encabezada por Pablo González. Para entonces, la planta productiva de las haciendas azucareras estaba seriamente estropeada dada la escalada destructiva de la guerra. Los propietarios pronto comenzaron a movilizarse para rehacerse, pensando en restablecer las haciendas y la producción azucarera. Junto con el declive de las haciendas, para el lastimado estado de Morelos asomaba un escenario sombrío que hacía tambalear su existencia: la baja demográfica, emigraciones, enfermedades y la quiebra de la hacienda pública estatal (Anaya Merchant, 2010:26-27). Estaba en juego la sobrevivencia de Morelos como estado de la federación y las haciendas como el alma de su economía.

El estado de Morelos había sido el principal escenario del zapatismo entre 1911 y 1919, año del asesinato de Emiliano Zapata. La lucha del Ejército Libertador del Sur se había distinguido por la defensa radical de las ideas contenidas en el Plan de Ayala (Pineda Gómez y Castro Zapata, 2013). Para 1919, la revolución popular suriana estaba al punto de la extenuación. Un par de años antes la corriente carrancista promulgó una nueva Constitución, pero el contenido agrario plasmado en su artículo 27, no fue el mismo que el defendido por el zapatismo. Además, la ley reguladora de este artículo constitucional sería la Ley Agraria del 6 de enero de 1915, redactada por Luis Cabrera que los zapatistas habían considerado insuficiente, lo que a la larga generaría paradojas y frenos en la aplicación de la reforma (James, 2010:60).

En oposición al ideal zapatista, la Constitución de 1917 estableció las bases para una reestructura agraria en la que el principal agente era la "Nación" y no los "pueblos" y en el que la idea de la propiedad privada tenía un papel primordial. Como señaló John Womack, el movimiento zapatista había sido el primero en pronunciarse en contra de "las definiciones oficiales de la revolución [...] y las limitaciones que las autoridades querían imponerle a la revolución" (Womack, 1997: s/p). 
Durante la etapa revolucionaria, fueron los grupos de corte social-popular quienes señalaron la necesidad de cambiar la estructura del campo mexicano. Desde antes y durante la etapa revolucionaria, autores como Wistano Luis Orozco (1974) o Andrés Molina Enríquez (1989) hablaron de las afectaciones que causaba el latifundismo a la sociedad y los pueblos mexicanos. Luis Cabrera propuso la restitución de tierras o la dotación de ejidos a los pueblos y lo plasmó en la mencionada Ley del 6 de enero de 1915 (Rivera Castro, 1988:21).

El zapatismo había expuesto una lucha frontal contra el latifundismo, así como a favor de la reivindicación de los pueblos y la defensa del campesinado. Esto le generó adeptos, pero al mismo tiempo, provocó recelo y desconfianza entre los grupos de poder, escépticos e incluso agresivos ante los alcances de un movimiento de corte indígena y campesino. Pero aún en tiempos cercanos a la promulgación de la Constitución de 1917, el gobierno carrancista dudaba de los beneficios que podía traer la destrucción del viejo orden a cambio de mejorar las condiciones en el campo mexicano (Rivera Castro, 1988:21).

Tanto Carranza como los gobiernos estatales impuestos en Morelos por su administración, atendieron diligentemente los reclamos de los terratenientes que vieron afectados sus intereses por el torbellino revolucionario. Puede considerarse que la etapa neo constitucional del carrancismo fue de estancamiento o continuidad del estado de cosas anterior a la lucha armada. Pero la devastación de la planta productiva, y las nuevas definiciones constitucionales y legales, fueron condicionando replantearse las directrices. Colocado en el poder nacional, el carrancismo socavó las bases del reparto zapatista implementado en años anteriores, cuando la jefatura del Ejército Libertador del Sur puso en práctica los postulados del Plan de Ayala (Pineda Gómez, 2013a; 2013b).

En tiempos de la Soberana Convención Revolucionaria (1915-1916) cuando se estableció en Morelos, la comandancia del Ejército Libertador del Sur definió acciones para restituir terrenos usurpados a los pueblos por las grandes haciendas. La comandancia zapatista conformó en Cuernavaca un consejo ejecutivo para coordinar la restitución de tierras y dotación de ejidos. Para ello y basándose en el Play de Ayala, promulgó la Ley agraria del 26 de octubre de 1915, que respondía a las insuficiencias que a juicio de la jefatura zapatista, tenía la Ley Agraria del 6 de enero de 1915 (Ávila Sánchez, 2002:81).

El cuartel zapatista urgió el deslinde de los terrenos expropiados para solucionar litigios y conflictos entre los pueblos. El papel fundamental en este proceso lo tuvieron las Comisiones Agrarias del Sur, integradas por estudiantes y pasantes en la Escuela Nacional de Agricultura de Chapin- 
go. Pero hacia finales de 1917, el grupo en el poder declaró nulas estas acciones agrarias (Ávila Sánchez, 2002:82).

Las muestras de hostilidad hacia los zapatistas por parte del gobierno central daban seguridad a los hacendados. Desde los inicios del nuevo régimen constitucional, los terratenientes morelenses emplearon mecanismos legales como el amparo o los juicios civiles, pues la Ley Agraria del 6 de enero establecía el derecho de los propietarios a acudir a los tribunales por prácticas que consideraran abusivas. De esa manera el uso del amparo por los terratenientes creció exponencialmente por todo el país y los morelenses siguieron esa tendencia. Para el año de 1927 Luis Cabrera estimó que la Suprema Corte de Justicia recogió en todo el país más de cinco mil amparos contra la reforma agraria. La práctica continuó hasta que una enmienda al artículo 10 de dicha ley en 1931 impidió que los propietarios siguieran amparándose ante la reforma agraria (James, 2010:57, 59).

Otros eventos fueron marcando el destino del sistema de haciendas en Morelos. Gildardo Magaña, sucesor de Emiliano Zapata como cabeza del Ejército Libertador del Sur, negoció un acercamiento con Venustiano Carranza. El asesinato de Zapata en abril de 1919 derivó en un crucigrama de desencuentros en torno a la figura del Zapata-símbolo (Pineda Gómez, 2011), y del contenido agrario del Plan de Ayala.

La promulgación del Plan de Agua Prieta en abril de 1920 desconoció la presidencia de Venustiano Carranza. Como reseña Francisco Pineda:

A mediados de 1920, Venustiano Carranza fue derrocado y asesinado. Los jefes carrancistas de Sonora [...] asumieron entonces el control del aparato estatal, por más de una década. El acontecimiento fue mayor, porque enseguida desapareció el Ejército Libertador y, casi simultáneamente, Pancho Villa se rindió. Las revoluciones del sur y del norte habían llegado al límite del agotamiento y fueron doblegadas (Pineda Gómez, 2011:211).

Al movimiento de Agua Prieta se unieron jefes surianos dispersos. Un grupo derrotado como el zapatismo tuvo entonces alternativas para la negociación.

El movimiento de Agua Prieta sembró dudas entre los terratenientes de Morelos, pues la alianza entre sonorenses y zapatistas podía derivar en una política agraria radical, ausente en las disposiciones conservadoras de Venustiano Carranza, quien se inclinaba a restituir el viejo orden (Domínguez Rascón, 2003:61-62. Adolfo de la Huerta arribó a la presidencia provisional del país en mayo de 1920 y en junio promulgó la Ley de Tierras Ociosas. 
Los acuerdos con los sonorenses motivaron que diversos jefes zapatistas apoyaran la candidatura de Álvaro Obregón. Con ello, se dieron enroques que abrieron al zapatismo alternativas desconocidas durante la guerra. Los compromisos adquiridos se evidenciaron cuando renombrados zapatistas tomaran posiciones cerca de la administración pública. Antonio Díaz Soto y Gama fundó el Partido Nacional Agrarista, Genovevo de la O asumió la comandancia militar del estado de Morelos, Jenaro Amezcua fungió como agente de la Secretaría de Agricultura y Fomento en Cuernavaca, a Miguel Mendoza L. Schwerdtfeger se le otorgó la presidencia de la Comisión Nacional Agraria (Anaya Merchant, 2010:29).

Un movimiento clave se dio cuando José G. Parres fue nombrado gobernador del estado de Morelos en 1920. Las alianzas sonorenses-zapatistas daban sentido a los ideales agraristas. Parres llevó a cabo un importante reparto agrario durante su gestión, con la figura de Emiliano Zapata como símbolo inherente. Organizó el primer homenaje institucional para Zapata el 10 de abril de 1921, apenas a dos años de su asesinato. Y aunque en un principio se trató de un homenaje popular, rápidamente se convirtió en un acontecimiento donde anualmente comenzaron a asistir personajes con aspiraciones políticas (Pineda Gómez, 2011:222). En contraposición, fue más clara la resistencia de los hacendados para enfrentar la disolución de los regímenes de propiedad a que estaban habituados, pero esta obstinación tendría un lento ocaso. Así fue el itinerario del estado de Morelos durante los años 20: encausado por la exigencia de los gobiernos nacional y estatal por hacer coincidir una contradicción originaria entre lo revolucionario y lo institucional.

El propio Obregón, el 27 de octubre de 1920, ya en vías de tomar la presidencia del país, indicó los alcances del reparto agrario diciendo que:

Debemos proceder con un tacto tal, que satisfaga el problema agrario sin poner en peligro nuestro bienestar [...]. No debemos destruir las propiedades grandes, antes de crear las pequeñas, porque vendría un desequilibrio de producción que pudiera quizá orillarnos a un período de hambre (Anaya Merchant, 2010:37).

Venía enseguida una exaltación del zapatismo sin una correspondencia con la acción institucional. Como señala Francisco Pineda:

En los años en que se comenzaba a institucionalizar la figura de Emiliano Zapata, Álvaro Obregón como presidente de la República envió al Congreso el proyecto de ley para fraccionar los latifundios y dotar a los campesinos. Al año siguiente, justo el 10 de abril de 1922 expidió dicho 
código aprobado por el Congreso como reglamento de la Ley Agraria. Así, por voluntad expresa del gobierno, la muerte de Emiliano Zapata quedó ligada con el nacimiento de la Reforma Agraria. Y, de ese modo, instituyó el principio que instituyó al jefe rebelde en "mártir" y su asesinato se volvió "semilla fecunda". (Pineda Gómez, 2011:222)

Tan pronto como nació la Reforma Agraria, el Estado proclamó que el artículo 27 constitucional no tendría ningún efecto retroactivo. Es decir, por medio de una argucia de barandilla, desconoció los derechos históricos de los pueblos y la usurpación colonial de tierras, montes y aguas. El régimen "emanado de la revolución" simulaba exaltar al zapatismo cuando, en verdad, lo reducía (Pineda Gómez, 2011:228).

Con una trayectoria errática, el estado de Morelos entró en un proceso de reconstrucción, que hacia los años 30 alcanzó a una etapa de definición. Para entonces estaba trazada una reconfiguración del territorio estatal basado en consecutivos repartos de tierras. En 1929 la Comisión Nacional Agraria dio por terminado el reparto en Morelos y para 1930, el $48 \%$ de la superficie total del estado había sido afectada por las leyes agrarias (Ávila Sánchez, 2002:90). Fue en el año de 1930 que se restableció el orden constitucional y los poderes estatales, representado por la elección de Vicente Estrada Cajigal como gobernador constitucional. Por último, para los años 30 se logró concebir la ruta hacia el colapso de la propiedad hacendada, cuando los terratenientes se vieron limitados para acudir a los tribunales a ampararse contra las acciones dotatorias y restitutorias de tierras (Patiño Flota y Espinoza Villela, 2015:29). Debido a ello, sólo pudieron buscar indemnizaciones por los daños sufridos durante la Revolución, a fin de buscar recuperar, al menos en parte, las pérdidas resultantes de la lucha armada. ${ }^{3}$

\section{Amparo y arrendamiento}

La política nacional al triunfo del Plan de Agua Prieta generó nerviosismo entre los terratenientes. La alianza entre sonorenses y zapatistas provocó incertidumbre en materia agraria. El carrancismo pareció apostar al restablecimiento del viejo orden en que los hacendados tenían un papel preponderante. Como mencionamos, la Ley del 6 de enero de 1915, incorporada al artículo 27 constitucional, establecía el derecho de los terratenientes a acudir a los tribunales por acciones dotatorias o restitutorias de

$3 \quad$ AHCCJ-Mor., Serie Civil, Exp. 2,1930. 
tierras que consideraran perjudiciales, lo que abrió el camino a la interposición del recurso de amparo y obstaculizaba la reforma agraria (Patiño Flota y Espinoza Villela, 2015:28-29).

Durante la etapa más aguda de la Revolución del Sur, los hacendados de Morelos prefirieron manejarse con un bajo perfil, refugiándose en la capital. Pero a finales de 1919 y principios de 1920, gracias a las gestiones de un grupo de terratenientes, Carranza accedió a restituirles sus tierras, mismas que comenzaron a trabajar de inmediato. Los hacendados contaban con la experiencia histórica de que la justicia fallaría a su favor, ratificando sus derechos sobre las tierras. Terratenientes como Manuel Araoz, la familia Amor y Luis García Pimentel iniciaron procesos judiciales para impedir cualquier afectación a tierras que consideraban suyas. Para reafirmar sus derechos de propiedad se dedicaron a trabajar las tierras a pesar de la devastación de la planta productiva y, en diferentes casos, optaron por arrendar terrenos (Rojano García, 2007).

Pero el trabajo de los hacendados de pronto se cruzó con la política agraria de Adolfo de la Huerta y con las intenciones de ayuntamientos y poblaciones que pugnaban por las tierras. Como mencionamos antes, Adolfo de la Huerta decretó en junio de 1920 la Ley de Tierras Ociosas que ponía a disposición de la Nación aquellas tierras laborables no cultivadas. Dicha ley establecía que los ayuntamientos podían dar las tierras ociosas en aparcería o arrendamiento a quien la solicitara (Domínguez Rascón, 2003:62). Este punto generó conflicto por la interpretación de la ociosidad de las tierras y la participación de los ayuntamientos como agente arrendador.

Además de ello, cuando el Dr. José G. Parres estableció su gobierno en Cuernavaca en 1920, dictó uno de los puntos destacados de su naciente administración. El 4 de septiembre de 1920 expidió el decreto número 5 en el que daba a conocer los lineamientos para iniciar al reparto agrario. Este decreto representaba, desde luego, un reconocimiento a la figura de Emiliano Zapata y al Plan de Ayala, pero al mismo tiempo, paradójicamente, implicaba cumplir un compromiso adquirido por el sector zapatista durante la unificación revolucionaria con los sonorenses: acatar las normas jurídicas establecidas en la Ley del 6 de enero de 1915 y en el artículo 27 de la Constitución del 1917 (Rojano García, 2007). Aunque con una base de contradicción, el reparto agrario se puso en marcha.

El primer paso para iniciar el reparto sería elevar la categoría política de todas las poblaciones. El segundo sería instalar una Comisión Local Agraria que verificara la legitimidad de las peticiones derivadas de los comités particulares de los pueblos, los cuales rápidamente empezaron a organizarse. La primera restitución de tierras le fue simbólicamente con- 
cedida al pueblo de Anenecuilco, por considerarse como la cuna de la revolución agraria (Rojano García, 2007, pp. 34-35).

En contraparte, los hacendados actuaban para restablecer la industria azucarera y los viejos regímenes de tenencia de la tierra en la región. Comenzaron una campaña en la que se ostentaban como gente de trabajo. Para los terratenientes, la solución al "problema de Morelos" no era el fraccionamiento de las haciendas trazado por el reparto agrario, sino en buscar alianzas con capitales extranjeros para establecer un reducido y eficiente grupo de grandes ingenios centrales que elaboraran azúcar barata para el mercado internacional. Para los hacendados era clave la reconfiguración del escenario azucarero desde sus necesidades empresariales y apelando al futuro fiscal del estado: "de no devolver cuanto antes las tierras a sus legítimos propietarios, y de no favorecer en lo posible el restablecimiento de la industria azucarera, se condena al estado a desaparecer como entidad federativa independiente" (Vélez, 1921, cit. en Rojano García, 2007, p. 16).

La compleja transición por la que atravesó el tema de la tenencia de la tierra en un estado de Morelos en vías de reconstrucción se reflejó de una manera clara en las haciendas de Santa Ana Tenango y Santa Clara Montefalco, ubicadas en el oriente del estado de Morelos, de las que Luis García Pimentel Elguero (Luis García Pimentel Jr., como aparece en la documentación) era el apoderado legal de éstas, mismas que eran propiedad de su padre, don Luis García Pimentel Sr. Para la familia García Pimentel, el ocaso de las haciendas era un asunto que iba más allá de lo empresarial. Las de Santa Ana Tenango y Santa Clara Montefalco habían estado en manos de su familia por más de 150 años. ${ }^{4}$

Revoluciones, alzamientos, conflictos por tierras y aguas con las comunidades vecinas, así como desencuentros con diferentes gobiernos habían sido frecuentes a lo largo de los siglos anteriores, logrando siempre mantenerse en pie (Pitmann, 1989). Debido a ello, al inicio de la Revolución del Sur, los terratenientes no habían considerado que esta forma de propiedad podía desaparecer. Don Luis García Pimentel, dueño de las mencionadas haciendas hasta su muerte en 1930, tuvo ocho hijos que llevaron el apellido García Pimentel Elguero: Luis (apoderado legal de su padre), Joaquín, Dolores, Rafaela y Guadalupe, más tres que murieron prematuramente, Susana, José Hilario y Miguel (Toussaint, 2008, pp. 33-34).

4 Formaron parte de esta notable estirpe empresarial los también historiadores, bibliógrafos y escritores, Joaquín García Icazbalceta (1825-1894) y su hijo Luis García Pimentel (1855-1930), de quienes hay interesantes estudios recientes (Rivas Mata y Gutierrez, 2013; Moguel Pasquel, 2017). 
Con posterioridad al asesinato de Zapata, García Pimentel Elguero intentó reactivar el cultivo de la tierra y actuó por la vía legal para sostener su proyecto de reedificar la industria azucarera. La devastación de la planta productiva no motivó el abandono de sus tierras. Por el contrario, García Pimentel Jr. buscó los mecanismos para reafirmar sus derechos sobre ellas, por ejemplo, mediante la implementación de estrategias de arrendamiento. Llama la atención que en los arreglos de arrendamiento de tierras de 1920 aparezca el nombre de Serafín Robles, quien durante la Revolución fue secretario de Emiliano Zapata. ${ }^{5}$ El hacendado también intentó reservar para sí el uso del agua, y que, en todo caso, la dotación de ejidos se hiciera únicamente con terrenos de temporal.

En este sentido, destaca un juicio de amparo que promovió Luis García Pimentel Elguero, a nombre de su padre, contra actos del presidente municipal de Tepalcingo a partir del 19 de mayo de 1921. El alcalde había otorgado en arrendamiento tierras que, en su opinión y bajo lo señalado por la Ley de Tierras Ociosas de 1920, permanecían inactivas. Sin embargo, García Pimentel se daría a la tarea de explicar que dichas tierras, ni carecían de dueño ni estaban ociosas: habían sido arrendadas bajo legítimo contrato y acusaba a las autoridades de violar sus derechos de petición y de debido proceso. El punto de conflicto es que, como se señaló, dicha ley promulgada durante la administración de Adolfo de la Huerta ponía a disposición de los ayuntamientos las tierras ociosas para darlas en aparcería o arrendamiento a quien la solicitara (Domínguez Rascón, 2003:62).

El 21 de mayo, Luis García Pimentel Elguero se dirigió al juez de primera instancia en Cuautla a fin de "demandar el amparo de la justicia de la unión contra actos del presidente municipal de Tepalcingo". El motivo de su recurso era que el presidente de Tepalcingo había declarado "tierras ociosas a las de temporal que forman los campos llamados 'Mirador', 'Rodeo', 'Retamilla', 'Palos Altos', 'Palo Amarillo', 'Mano Pintada' y 'Marranero', pertenecientes a la Hacienda de Tenango". De acuerdo con el hacendado, el presidente municipal había dispuesto unilateralmente poner "en posesión de ellas para que las cultiven en el presente año labrador a varios individuos cuyos nombres y lugar de residencia ignoro," pese a que las tierras ya habían sido subarrendadas a "los señores Miguel Rebollo, Cenobio Rico, Miguel Olvera y Antonio Valdepeñas, según General de la Nación, Fondo Genovevo de la O (FGO), Caja 26, Exp. 2, Fols. 34-37, cit. en Rojano García, 2007:44. 
contratos que obran en mi poder", y quienes sólo esperaban el temporal "para dar principio a sus trabajos de labranza". ${ }^{6}$

Con acciones legales como la anterior, García Pimentel Elguero buscaba reivindicar los derechos de su familia sobre las tierras que consideraba como propiedad de las haciendas de Santa Clara Montefalco y Santa Ana Tenango. Por medio de un aviso dirigido a los pueblos cercanos a sus fincas, con fecha de 8 de mayo de 1921, García Pimentel afirmaba que estaba enterado de que había personas que "aconsejan a los sembradores" para que firmaran contratos de arrendamiento con los ayuntamientos y no con el arrendatario general de dichas tierras, el español José Rico. García Pimentel Elguero consideraba que con el arrendamiento sancionado por los ayuntamientos, "con objeto de entrar en posesión de las mismas por medio de solicitudes en calidad de tierras ociosas, alegando los campesinos que por este procedimiento dejarán de reconocer la validez de la propiedad del dueño de las haciendas", 7 aunque razonaba que la Ley de Tierras Ociosas reconocía tácitamente la propiedad de los hacendados.

En este aviso García Pimentel también estableció las directrices para el arrendamiento y ofrecía dar condiciones tan convenientes, "tan benéficas como las establecidas por la ley de tierras ociosas siempre que firmen con el arrendatario los contratos en vez de firmarlos con los ayuntamientos". El hacendado ofrecía descuentos en el pago por la cosecha y en los adeudos por rentas atrasadas, insistiendo en la conveniencia del contrato con la hacienda, pues de "firmar contratos con los ayuntamientos tendrán muchos emperadores que pagar rentas mayores que las acostumbradas, y por lo tanto más les conviene tomar las tierras en arrendamiento el Sr. Rico". Para el hacendado, por el hecho de hacer acuerdos con el ayuntamiento, "tendrían que pagar en muchos casos mayor renta que la acostumbrada en años anteriores y no dejaría de reconocerse explícitamente la propiedad del hacendado respecto de estas tierras". García Pimentel, además, hacía ver a los pobladores que "la Justicia Federal acaba de ampararme en un caso de solicitud de tierras ociosas muy semejante [...] lo que hace que si me viera precisado a recurrir nuevamente la justicia, lo más probable es que obtendría yo un fallo favorable". En su despedida, el propietario exhortaba a los habitantes: "espero que los interesados comprenderán el espíritu conciliatorio de mi ofrecimiento y las ventajas que este nos proporciona". ${ }^{8}$

\footnotetext{
$6 \quad$ AHCCJ-Mor., Amparos, Exp. 34, No. 1353, 1921, fs. 1-3.

7 AHCCJ-Mor., Amparos, Exp. 34, No. 1353, 1921, f. 10.

8 AHCCJ-Mor., Amparos, Exp. 34, No. 1353, 1921, f. 10.
} 
José Rico era el arrendatario general de las haciendas de Santa Clara y Tenango, y fungía como interlocutor entre hacendados y pueblos. José Rico, súbdito español, era señalado por los campesinos del municipio de Jonacatepec por ejercer prácticas vejatorias: desviar las aguas hacia la hacienda e imponer gabelas a los pueblos. Rico contaba con gente armada y, con uso de la fuerza, persuadía a los campesinos para que dejaran de solicitar ejidos o incurrir en algo que dejara fuera de los tratos a sus jefes. (Rojano García, 2007, p. 43).

A todos los pueblos que están comprendidos dentro de las Haciendas a su cargo los extorsiona, los veja y denigra solamente que por que todos ellos, como fue su única aspiración están gestionando la restitución de sus ejidos. Su cólera no tiene límites, cuando los humildes naturales no quieren firmar con él contratos de arrendamientos de las tierras o aparcería [...] Todavía su cólera es mayor y sus amenazas y denuestos son más candentes, cuando sabe que alguna persona ha solicitado sembrar algunas tierras por creerla ociosa. ${ }^{9}$

El alegato del hacendado continuó. El alcalde de Tepalcingo pidió que Ricardo Sarmiento, presidente interino de la Comisión Local Agraria del Estado, lo representara en este caso. Uno de los resultados de la inspección fue que la ocupación que acusaba García Pimentel sólo se había dado en dos terrenos y no en los siete que argumentaba. Sin embargo, la representación del hacendado decía que a pesar de ser pocos los terrenos, había materia de amparo, pues en la disposición del ayuntamiento de Tepalcingo, había violaciones a lo dispuesto por la ley delahuertista. En su opinión, aunque el presidente municipal aseguraba haberse basado en la ley del 23 de junio de 1920 "estuvo muy distante la autoridad de la observancia estricta de lo que la referida ley ordena porque ni las tierras estaban ociosas ni el tiempo en que se ejecutaron los actos reclamados eran aún propicios para iniciar los trabajos de labranza". Además, el arrendatario general de Tenango, José Rico, no podía considerar la ociosidad de las tierras, pues desde febrero dio algunas en arrendamiento "al Sr. Cenobio Rico, según consta en el contrato privado que exhibo". La defensa del hacendado argumentaba que "la ociosidad de las tierras para los efectos de la ley de referencia no depende de que estén o no arrendadas éstas, sino de que en realidad no estén cultivadas". ${ }^{10}$ Vecinos de Jonacatepec a la Secretaría de Gobernación, mayo de 1921, AGN, Fondo Presidentes Obregón-Calles, 818-J-5, cit. en Rojano García, 2007:43.

10 AHCCJ-Mor., Amparos, Exp. 34, No. 1353, 1921, fs. 42-43. 
Uno de los documentos más interesantes que se encuentran en el expediente judicial que hemos venido refiriendo, es el contrato de arrendamiento firmado por el Sr. Cenobio Rico con el Sr. José Rico, para trabajar los terrenos de "Retamilla", "Palos Altos", "Palo Amarillo" y "Mano Pintada". Cenobio Rico, subarrendatario, tenía prohibido cortar los árboles; además de que al levantar la cosecha, estaba obligado a entregar maíz y zacate de buena calidad. También estaba obligado a cercar y vigilar los terrenos, y a cuidar que el ganado no dañara la obra hidráulica. ${ }^{11} \mathrm{El}$ documento es relevante por la problemática en medio de la que fue elaborado. Existen referencias que señalan que José Rico vociferaba que "tan bandidos eran los pueblos como los ingenieros agraristas y el mismo gobierno". Los campesinos de la región amenazaron con ajustar cuentas con José Rico. ${ }^{12}$ De tal magnitud fue el problema que llamó la atención del Dr. Parres y del gobierno federal, quienes pidieron la expulsión del administrador a fin de no deteriorar las relaciones entre México y España. ${ }^{13}$

Es importante mencionar que en el campo del estado de Morelos, el arrendamiento no era desconocido. Aunque los pueblos tradicionalmente asumían que las tierras les habían sido usurpadas, un sector de campesinos acostumbraba a rentarlos regularmente. Sin embargo, el arrendamiento ha quedado diluido en la reflexión de las disposiciones acerca de la tenencia de la tierra, centradas en lo señalado por el Plan de Ayala. Los rancheros y otros agentes del espectro rural morelense muchas veces desempeñaron sus labores en terrenos alquilados en los que hacían siembras distintas a las requeridas por la producción azucarera de las haciendas, principalmente maíz, arroz, verduras y frutas (Barreto Mark, 2013, p. 189).

Mejorar las condiciones del arrendamiento había formado parte de las preocupaciones sobre la tenencia de la tierra que expresaron los zapatistas antes de la promulgación del Plan de Ayala en noviembre de 1911. Se puede decir que entre los meses de mayo y junio de 1911, la figura del arrendamiento de tierras permaneció activa en el lenguaje de los rebeldes y se consideró al menos durante la primera fase revolucionaria (Barreto Mark, 2013:189, 191). Zapata buscó hacer respetar antiguos derechos incluso en tierras dadas en arrendamiento (Barreto Mark, 2013: 190). Las medidas que el zapatismo tomó respecto al problema de la tierra incrementaron su nivel de radicalidad conforme avanzó el proceso revolucio-

\footnotetext{
11 AHCCJ-Mor., Amparos, Exp. 34, No. 1353, 1921, f. 44.

13 Ibídem., pp. 43-44.
} 
nario y el arrendamiento se fue desvaneciendo. Pero una vez pasada la etapa armada de la revolución, el arrendamiento volvió a considerarse.

El proceso continuó. En contraparte, Ricardo Sarmiento, representante del presidente municipal y de la Comisión Local Agraria del estado, negó que se hubieran cometido las irregularidades denunciadas por García Pimentel Elguero y su gente. Sarmiento argüía una malintencionada interpretación de la ley por lo que no había violaciones que señalar, pues la disposición de los terrenos tuvo fundamento en el artículo 27 de la Constitución de 1917 y la Ley de Tierras Ociosas de 1920:

Señor juez de distrito del Estado

Presente [...]

El señor Luis García Pimentel Jr. como apoderado del señor su padre Don Luis García Pimentel Sr., demandó el amparo de la justicia federal contra los actos del ciudadano presidente municipal de Tepalcingo [...] Debo afirmar respetuosamente que tales violaciones no han existido. En efecto, se trata de la aplicación de la Ley Federal del 23 de junio de 1920, expedida para el aprovechamiento de las Tierras Ociosas en la República [...]

Ninguna prueba se ha presentado por el demandante contraria a las fehacientes exhibidas por el ciudadano presidente municipal de Tepalcingo. Es pues infundada la demanda [...]

En su argumentación, el demandante confunde lastimosamente la interpretación de la ley y trata de hacer ver que el hecho de haberse sub arrendado por el arrendatario de la hacienda de Tenango a personas distintas de los concesionarios favorecidos por el Ayuntamiento de Tepalcingo las tierras concedidas a estos demuestra a su juicio que no estaban ociosos. La magnitud del dislate a nadie se oculta; pero no es por demás hacer referencia al artículo segundo de la ley de 23 de junio de 1920 que se promulgó el 25 de julio de 1920 que dice textualmente: "Todas aquellas tierras que sus dueños o poseedores haya aprovechado o puesto en cultivo, pasadas las fechas que marca la ley para su preparación en diciembre, quedarán por ese solo hecho a disposición de los ayuntamientos para los efectos de la presente ley" [...]

Por lo expuesto suplico respetuosamente a este tribunal a quien me dirijo se sirva resolver negativamente a demanda interpuesta por el señor Luis García Pimentel Junior [...]

Cuernavaca, Morelos, a 22 de julio de 1921.

R. Sarmiento. ${ }^{14}$

${ }_{14}$ AHCCJ-Mor., Amparos, Exp. 34, No. 1353, 1921, pp. 64-66. 
La interpretación legal que dieron las autoridades a este caso derivó en que el amparo fuera otorgado. Luis García Pimentel Elguero tuvo razón cuando consideró que lo más seguro era que se lo otorgaran. La "narrativa obvia", de acuerdo con James, es que los tribunales se mostraban antiagrarios y el Poder Judicial se presentaba como un obstáculo, debido a los huecos dejados en la ley preconstitucional del 6 de enero como reguladora (James, 2010:60). Pese a la impugnación de la decisión por parte de Ricardo Sarmiento, la Suprema Corte reiteró el fallo: se otorgaba el amparo contra los actos que se consideraron violatorios. Los hacendados aún podían encontrar cauces legales. Cualquier acto contra las haciendas era considerado por sus propietarios como un despojo, lo que se cruzaba con la imposibilidad de que los campesinos locales produjeran a gran escala. A juicio de los hacendados, al tiempo, los campesinos serían incapaces de hacer producir la tierra morelense. "El hambre nos acosará a todos", decían, ese sería "el gran triunfo de los agraristas" (Rojano García, 2007, p. 48).

Pero las circunstancias de la Revolución sacudieron a los García Pimentel. Los acontecimientos de la década de los 20, aunque complicados, les permitió abrigar esperanzas para la reconstrucción de su gloria azucarera. Sus derechos como landlords se fueron erosionando poco a poco en medio de una intrincada maraña legal. Antes del reparto, Santa Ana Tenango contaba con una extensión de 38,679 has. y Santa Clara 29,480 has. Pero esta unidad territorial se fue desvaneciendo.

Múltiples solicitudes de dotación de tierras y aguas por parte de los pueblos de Morelos cuartearon la unidad de su producción. Los pagos que las aseguradoras ofrecieron a los hacendados fueron insuficientes para su proyecto de reconstrucción, por lo que trataron de ajustarse a la ley de la Deuda Pública que sentaba las bases para escuchar reclamos por daños causados por la Revolución. Acudieron a la Comisión Ajustadora de la Deuda Pública Interior, ocupada de reclamaciones como la suya (Solórzano, 2002:425).

Pero, para esos años, los hacendados estaban ante la erosión de su enorme poder. En un juicio civil de 1930 se muestra que Luis García Pimentel Elguero se apoyó en peritos de la talla del célebre como el ingeniero agrónomo Felipe Ruiz de Velasco para evaluar los daños a sus propiedades y así negociar la indemnización. Al igual que los García Pimentel, Ruiz de Velasco consideraba que el futuro del estado de Morelos estaba en la recuperación de la hacienda azucarera, como lo plasmó en su obra Historia y evoluciones del cultivo de la caña (1937). Los argumentos de Ruiz de Velasco en su peritaje reflejaban la idea de la grandeza pasada de las haciendas. Valuó los daños de Santa Ana Tenango y Santa 
Clara Montefalco en $\$ 1^{\prime} 773,340$, pero un peritaje del gobierno lo redujo drásticamente a $\$ 600,194$. Un tercer peritaje solicitado por el hacendado apenas los colocó en $\$ 617,194 .{ }^{15} \mathrm{El}$ proceso de indemnización además se vio afectado por la reducción del gasto público a consecuencia de la crisis de 1929. Don Luis García Pimentel Sr. murió en 1930.

Para los años 30 , con la planta productiva sin visos de una franca recuperación y con la disposición de tierras reducida, los García Pimentel, al igual que otros hacendados, estaban ante el ocaso de sus propiedades. Además, en 1931 se dio una enmienda al artículo 10 de la Ley agraria del 6 de enero de 1915, por medio de la cual los propietarios afectados no podrían tener acceso a amparos quitando derechos de acudir los tribunales a los terratenientes. Dicha enmienda decía que:

Los propietarios afectados con resoluciones dotatorias o restitutorias de ejidos o aguas, que se hubiesen dictado en favor de los pueblos, o que en lo futuro se dictaren, no tendrán ningún derecho ni recurso legal ordinario, ni el extraordinario de amparo. Los afectados con dotaciones tendrán solamente el derecho de acudir al Gobierno Federal para que les sea pagada la indemnización correspondiente (James, 2010, p. 58).

Bajo este escenario, la búsqueda de la indemnización continuó largamente, aunque se fue abandonando la intención de recuperar el esplendor de las haciendas. Para 1946 la Secretaría de Agricultura y Fomento comunicó un acuerdo firmado por el presidente Ávila Camacho para compensar a los herederos de Luis García Pimentel "por las afectaciones que sufrió la finca de su propiedad denominada 'Santa Clara y Jonacatepec' ubicados en el Estado de Morelos" con terrenos del sistema de riego del Río Purificación, en Tamaulipas. Se mencionan a Rafaela García Pimentel vda. de Bernal, Dolores García Pimentel vda. de Rivas, Guadalupe García Pimentel de Corcuera y Luis García Pimentel y Elguero. Los bienes de la hacienda fueron valuados entonces en $\$ 231,517$, y los terrenos por entregar en $\$ 41,527$, restando un saldo a favor de los afectados. ${ }^{16}$

\section{Comentario final}

El proceso histórico aquí analizado permite adentrarnos en la complejidad que confluyó en una etapa temprana del reparto agrario en Morelos, lo que llevaría al final del sistema de la gran hacienda azucarera. La idea

\footnotetext{
15 AHCCJ-Mor. Serie Civil, Exp. 2,1930.

16 Diario Oficial de la Federación, 27 de agosto de 1946, p. 5.
} 
central del texto es que los hacendados de Morelos, no se mantuvieron pasivos ante las afectaciones que trajo a sus propiedades la lucha revolucionaria, sino que optaron por iniciar procesos legales y acciones que serpenteaban la interpretación legal, a fin de mantener lo que consideraban sus derechos como propietarios y así canalizar sus intenciones de reconstruir la industria azucarera morelense.

Al optar por la vía legal, los hacendados promovieron amparos y procedimientos civiles para protegerse de lo que consideraban como abusos de las autoridades hasta que la ley les permitió utilizar esos recursos para argumentar en contra de la reforma agraria. Además, en la disputa por la tierra, trataron de mantener su predominio sobre los terrenos de siembra que no podían explotar, mediante contratos de arrendamiento que afirmaran sus derechos de propiedad y evitaran los efectos de leyes como la de Tierras Ociosas de 1920. Fueron animosos defensores de la legalidad que daba sentido a su propiedad sobre los terrenos de cultivo, hasta que en 1931 una enmienda a la Ley del 6 de enero de 1915 les impidió acudir a los tribunales para ampararse y los limitó a la posibilidad de pedir indemnización.

En su lucha legal, los propietarios de las haciendas azucareras participaron de las contradicciones inherentes a las medidas agrarias que proliferaron alrededor del nuevo orden constitucional basado en la Carta Magna de 1917, su artículo 27 y a la preconstitucional Ley del 6 de enero de 1915 como reglamentaria del reparto agrario. Estaba en juego un sistema de vida, un estado de cosas cuyos orígenes se remontaban al periodo colonial y del que la familia García Pimentel, propietaria de las haciendas de Santa Ana Tenango y Santa Clara Montefalco, era uno de sus ejemplos más acabados.

Pero el ocaso del latifundismo en Morelos no representó la culminación de los ideales zapatistas dispuestos en el Plan de Ayala, lo que generó diversas paradojas y nuevas fricciones derivadas del reparto agrario. Como vimos, contrario a una idea más o menos difundida, la Constitución de 1917, en su apartado relativo al tema de la tierra, no reivindicó directamente la lucha zapatista. Múltiples disposiciones legales formadas por el proceso revolucionario fueron generadas por corrientes distintas al zapatismo, por lo que a pesar de la evidencia del reparto agrario a la larga no se consiguió una solución definitiva al problema de la tierra con una visión que retomara claramente los preceptos del Plan de Ayala. En ese sentido, es importante sensibilizarse ante la evidencia de las colisiones entre las medidas agrarias revolucionarias y las institucionales. 


\section{Archivo y hemerografía:}

Archivo Histórico de la Casa de Cultura Jurídica de Cuernavaca, Morelos.

(AHCCJ-Mor.)

Sección Amparos

Sección Civil

Archivo General de la Nación. (AGN)

Fondo Genovevo de la O

Fondo Presidentes Obregón-Calles

Diario Oficial de la Federación

\section{Bibliografía}

Anaya Merchant, L. (2010).

Reconstrucción y modernidad. Los límites de la transformación social en el Morelos posrevolucionario. En M. V. Crespo, y L. Anaya Merchant (Coords.), Política y sociedad en el Morelos posrevolucionario, Tomo VIII de H. Crespo (Dir.), Historia de Morelos. Tierra, gente, tiempos del Sur, Congreso del Estado de Morelos (LI Legislatura), Cuernavaca: Gobierno de Morelos, Instituto de Cultura, de Morelos, Ayuntamiento de Cuernavaca, Universidad Autónoma del Estado de Morelos, pp. 25-54. Ávila Espinosa, F. (2001).

Los orígenes del zapatismo. Ciudad de México: El Colegio de México, Universidad Nacional Autónoma de México.

Ávila Sánchez, H. (2002).

Aspectos históricos de la formación de regiones en el estado de Morelos (Desde sus orígenes hasta 1930). Ciudad de México: Centro Regional de Investigaciones Multidisciplinarios, Universidad Nacional Autónoma de México.

Barreto Mark, C. (2013).

Entre campesinos, arrendatarios y el Plan de Ayala. Recuerdos y testimonios de una revolución. En F. Pineda Gómez, y E. Castro Zapata, (coords.), A cien años del Plan de Ayala. México: Era, pp. 175-201.

Crespo, H. (2000).

Los pueblos de Morelos. La comunidad agraria, la desamortización liberal en Morelos y una fuente para el estudio de la diferenciación social campesina. En L. Espejel López, Estudios sobre el zapatismo. Ciudad de México: Instituto Nacional de Antropología e Historia, pp. 57-120.

Crespo, H. (2009). Modernización y conflicto social. La hacienda azucarera en el estado de Morelos, 1880-1913. Ciudad de México: Instituto Nacional de Estudios Históricos de las Revoluciones de México. 
Domínguez Rascón, A. (2003)

La política de reforma agraria en Chihuahua, 1920-1924: sus efectos hasta 1940. Ciudad de México: Instituto Nacional de Antropología e Historia, Plaza y Valdés.

Escobar Ohmstede, A. y M. Butler (2013)

México in transition. New perspectives on Mexican Agrarian History. Nineteenth and Twentieth Centuries. Ciudad de México: Centro de Investigación y Estudios Superiores en Antropología Social, University of Texas at Austin.

Espejel López, L. (2000)

Estudios sobre el zapatismo. Ciudad de México: Instituto Nacional de Antropología e Historia.

James, T.M. (2010)

Revolución social e interpretación constitucional. La Suprema Corte y la reforma social revolucionaria, 1916-1934. Ciudad de México: Poder Judicial de la Federación.

Kourí, E. (2017)

Sobre la propiedad comunal de los pueblos, de la Reforma a la Revolución. Historia Mexicana, [S.1.], pp. 1923-1960.

López González, V. (2001)

La destrucción del latifundio en el estado de Morelos, 1920-1923.

Cuernavaca: Cuadernos Históricos Morelenses, Instituto Estatal de Documentación de Morelos.

Ludlow, L. (Coord.).

Los secretarios de hacienda y sus proyectos (1821-1933). Tomo II. Ciudad de México: Instituto de Investigaciones Históricas, Universidad Nacional Autónoma de México.

Moguel Pasquel, M. C. (2017).

Un empresario agrícola porfirista en Morelos. El caso de Luis García Pimentel. Secuencia, abril 2017, no. 97, pp.170-199.

Molina Enríquez, A. (1989).

Los grandes problemas nacionales. Ciudad de México: Era.

Orozco, W. L. (1974).

Legislación y jurisprudencia sobre terrenos baldíos. Ciudad de MéxiCo: El Caballito.

Patiño Flota, E. R. y Espinoza Villela, M. J. (2015).

Ley Agraria del 6 de enero de 1915: semilla de la propiedad social y la institucionalidad agraria en México. Estudios Agrarios, No. 58, pp. 17-39.

Pineda, F. (1997).

La irrupción zapatista, 1911. México: Era. 
Pineda Gómez, F. (2011).

Operaciones del poder sobre la imagen de Zapata, 1921-1935. En J. Haidar y G. Sánchez Guevara (Eds.), La arquitectura del sentido II. La producción y reproducción en las prácticas semiótico-discursivas. México: Escuela Nacional de Antropología e Historia, Instituto Nacional de Antropología e Historia, pp. 221-257.

Pineda Gómez, F. (2013a). Ejército Libertador, 1915. México: Era.

Pineda Gómez, F. (2013b).

El Plan de Ayala. Plan Libertador para acabar con la opresión y redimir a la Patria. En C. Barreto Zamudio, La Revolución por escrito. Planes político-revolucionarios del estado de Morelos. México: Gobierno del Estado de Morelos, pp. 91-117.

Pittman, D. K. (1989).

Hacendados, campesinos y políticos. Las clases agrarias y la instalación del Estado oligárquico en México, 1869-1876. México: Fondo de Cultura Económica.

Rivas Mata, E. y Gutiérrez L. E., Comp. (2013).

Cartas de las haciendas. Joaquín García Icazbalceta escribe a su hijo Luis, 1977-1894. México: Instituto Nacional de Antropología e Historia.

Rivera Castro, J. (1988).

Política agraria, organizaciones, luchas y resistencias campesinas entre 1920 y 1928. En E. Montalvo (coord), Historia de la cuestión agraria mexicana: modernización, lucha agraria y poder político, 1920-1934, tomo 4. México: Siglo XXI, Centro de Estudios Históricos del Agrarismo en México, pp. 21-149.

Rojano García, E. D. (2007).

Las cenizas del zapatismo, México: Universidad Autónoma del Estado de Morelos, Unidad Central para el Estudio del Desarrollo Social.

Rueda Smithers, S. (1999).

El paraíso de la caña, historia de una concepción imaginaria. México: Instituto Nacional de Antropología e Historia.

Ruiz de Velasco, F. (1937).

Historia y evoluciones del cultivo de la caña y de la industria azucarera en México, hasta el año de 1910. México: Cultura.

Solórzano, C. (2002).

Luis Montes de Oca: reorganización de la hacienda pública y reforma monetaria, 1927-1931. En L. Ludlow (coord.), Los secretarios de hacienda y sus proyectos (1821-1933), Tomo II, México: Instituto de Investigaciones Históricas, Universidad Nacional Autónoma de México, pp. 413-440. 
Sotelo Inclán, J. (1943).

Raíz y razón de Zapata, México: Etnos.

Tortolero Villaseñor, A. (2008).

Notarios y agricultores. Crecimiento y atraso en el campo mexicano, 1780-1920. México: Universidad Autónoma Metropolitana-Iztapalapa, Siglo XXI.

Toussaint, A. (2008).

Haciendas de Morelos. México: Fideicomiso Turismo Morelos.

Valladares, L. (2003).

Cuando el agua se esfumó: cambio y continuidades en los usos sociales del agua en Morelos, 1880-1940. México: Facultad de Estudios Superiores Cuautitlán, Universidad Nacional Autónoma de México.

Vélez, F. (1921).

Dos escritos dirigidos a las autoridades por los hacendados de Morelos. México: Antigua Imprenta de Murguía.

Warman, A. (1976).

$Y$ venimos a contradecir. Los campesinos de Morelos y el Estado naCional. México: Ed. De la Casa Chata.

Womack, John Jr. (1969).

Zapata y la Revolución Mexicana. México: Siglo xxI.

\section{Medios electrónicos}

Durán, C. L. (1999).

Apuntes sobre la fuente judicial como recurso para la investigación social. Sociohistórica, 6. Recuperado de: http://www.fuentesmemoria. fahce.unlp.edu.ar/art_revistas/pr.2815/pr. 2815.pdf

Consultado el 6 de abril de 2017.

Womack, J. Jr. (1997).

El Plan de Ayala. Nexos, 1 de marzo de 1997. https://www.nexos.com. $\mathrm{mx} / \mathrm{p}=8218$

Consultado el 8 de agosto de 2017. 
